This is a PDF file of an unedited manuscript that has been accepted for publication in Applied Energy. The manuscript will undergo copyediting, typesetting, and review of the resulting proof before it is published in its final form. Please note that during the production process errors may be discovered which could affect the content, and all legal disclaimers that apply to the journal pertain.

The final version will be available at: https://doi.org/10.1016/j.apenergy.2019.113881

\title{
Life beyond the grid: a life-cycle sustainability assessment of household energy needs
}

\author{
Yvonne Vogt Gwerder ${ }^{\mathrm{a}, \mathrm{c}}$, Pedro Marques ${ }^{\mathrm{a}}$, Luis C. Dias ${ }^{\mathrm{b}, \mathrm{c}}$, Fausto Freire ${ }^{\mathrm{a}}$, \\ a ADAI, LAETA, Department of Mechanical Engineering, University of Coimbra, Rua Luís Reis Santos, 3030- \\ 788 Coimbra, Portugal \\ ${ }^{b}$ CeBER, Faculty of Economics, University of Coimbra, Av. Dias da Silva 165, 3004-512 Coimbra, Portugal \\ c INESC Coimbra, Rua Sílvio Lima, Pólo II, 3030-290 Coimbra, Portugal \\ * Corresponding author: fausto.freire@dem.uc.pt
}

\begin{abstract}
This work assesses the sustainability of meeting electricity and heating needs in off-grid homes by performing a combined Life-Cycle Sustainability Assessment (LCSA) and Multi-Criteria Decision Analysis (MCDA) study on two off-grid houses in a rural village in Portugal. The sustainability of meeting energy needs in the off-grid homes, compared to using the grid, was found to be dependent on the indicators under consideration, the technologies used in the homes, and household energy needs. The current situation was compared to four energy provisioning scenarios using Multi-Attribute Value Theory (MAVT) to rank alternatives based on their sustainability performance. The considered scenarios evaluated the impacts of extending and connecting the grid to the homes to allow for either: electricity consumption from the grid, or both consumption and injection of excess electricity generated to the grid. The results showed that meeting household electricity and heating needs in a sustainable way requires an analysis of the local context and available resources. For remote homes, off-grid renewable energy solutions provide a reliable and sustainable form of energy. However, homeowners that live in places with close access to the electricity grid have higher impacts from living off-grid; in order to ensure reliability, the homes require multiple systems that can generate more electricity than the homeowners need, which contribute to higher life-cycle impacts. Thus, a consideration of trade-offs is central to understanding the value of alternative possibilities for energy provisioning.
\end{abstract}

\section{Keywords}

Off-grid homes; Local energy systems; Life-Cycle Assessment; Multi-Criteria Decision Analysis; Multi-Attribute Value Theory; Renewable energy 


\section{Introduction}

Off-grid households are defined as those that are disconnected from electricity and natural gas grids [1]. Technological innovations in small-scale generation paired with decreasing costs in renewables and storage have sparked public and academic curiosity about the sustainability of living off-grid [2]. Some citizens, spurred by access to reliable and clean decentralized energy, are starting to voice ideas about self-empowerment and independence from large energy companies [3]. Off-grid homeowners have the ability to harness locally available resources, and make themselves key constituents in the energy infrastructure [4]. Studying off-grid households, especially those comprised of members who have chosen to live this lifestyle, provides a window to evaluate and explore alternative means of energy provisioning. As a result, there is an increasing number of publications focused on evaluating off-grid energy systems, with life-cycle and decision analysis tools emerging as common assessment methodologies.

Life-Cycle Assessment (LCA) is an environmental management tool used to understand the full impacts of a product or activity from "cradle-to-grave" [5]. Since the early 2000s, there has been an elaboration in LCA, with the development of approaches such as: Life Cycle Costing (LCC), Social Life Cycle Assessment (S-LCA), and Life Cycle Sustainability Assessment (LCSA) [6]. LCSA is the newest method, which combines E-LCA, LCC, and S-LCA to evaluate all pillars of sustainability together [6], [7]. Although LCSA provides a holistic technique to evaluate sustainability impacts, it is difficult to compare alternatives and integrate results. Multi-Criteria Decision Analysis (MCDA) complements well because it allows for the aggregation of different measures.

MCDA is a collection of formalized approaches to account for multiple criteria while evaluating alternatives in the decision-making process [8]. These approaches usually assume the existence of a Decision-Maker (DM), who can be a single entity or a group that "owns the problem," and whose elicited preferences will affect the overall result and determine recommendations that are as compatible as possible with their values [9]. In this way, the purpose of MCDA is not to get an objective truth, but rather, to derive results that are a function of the DM's preferences. The application of MCDA to life-cycle studies has become increasingly popular in recent years, with studies ranging from: choosing alternative biodiesel chains [10], prioritizing bioethanol production pathways [11], choosing renewable energies net-zero energy communities [12], among other general frameworks [13]. The combination of life-cycle and decision analysis frameworks provides a comprehensive and methodological way to assess the impacts of complex systems, which can be readily applied in the case of off-grid homes.

Most of the pertinent life-cycle research for energy systems has focused primarily on gridconnected or large scale power systems [14]-[24], and only a few works evaluate smaller-scale energy systems [12], [25]-[31]. One of the main attributes of an off-grid household is that it requires the simultaneous functioning of multiple technologies in order to reliably meet household energy needs. To the authors' knowledge, only a few notable studies have focused on evaluating the interconnected energy systems: two analyzed the combination of solar photovoltaic microgrid systems to generate electricity in off-grid communities in Nigeria [32] and Kenya [33], while another compared a hybrid wind/microgrid/diesel system to power a village in Thailand [34]. Although these works assessed multiple technologies, they did not address the complexities of interconnected systems at a household level. The only study that looked at multiple systems at the household level is one by conducted by Üçtuğa \& Azapagic [30], where the authors evaluated the environmental life-cycle impacts of integrated multi- 
crystalline photovoltaic and lithium-ion battery hybrid systems in households. Yet, they did not take into consideration all aspects of sustainability. There are a few cases of combined lifecycle/decision analysis studies focusing on energy systems, however, these studies often do not have a DM involved, thus recommendations are not based on preferences. Instead, many LCA/MCDA studies circumvent the absence of a real DM by deriving multiple weight vectors [9], using different mechanisms such as sensitivity analyses [20], or fuzzy logic [35]. Although these works were able to apply decision analysis tools to integrate results, eliciting preferences from a DM would provide for a more realistic assessment.

Given the current state of research, it is clear that there is a gap of knowledge regarding the lifecycle sustainability impacts of off-grid homes. Furthermore, there is an opportunity to incorporate MCDA methods to integrate results and include off-grid homeowner's preferences and values. This research seeks to contribute to LCSA, MCDA, and renewable energy systems literature, while informing homeowners and the general public regarding the sustainability of meeting electricity and heating needs in off-grid homes. To achieve these objectives, we selected two off-grid households in Benfeita, a small village situated in the Arganil municipality of Portugal that has attracted an ecologically inclined community, to design a combined LCSA and MCDA study evaluating the environmental, economic, and social impacts and trade-offs of meeting electricity and heating needs in off-grid homes. The two homes were chosen because they have unique electricity and heating needs as well as distinct resource constraints that require the use of different technologies, making them representative of diverse challenges of off-grid living. By modeling two off-grid households including all required systems to deliver heat and electricity to the home, this work provides a systematic comparison of the environmental, economic, and social impacts of off-grid households, adding an additional perspective to the existing literature. The paper is structured as follows: Section 2 outlines the materials and methods applied to this study, Section 3 presents and discusses results, and Section 4 concludes with highlights and key outcomes as well as recommendations for off-grid homeowners.

\section{Materials and Methods}

Figure 1 presents the assessment framework, which is divided between the application of LCSA and MCDA methods. The LCSA portion of the study includes: the definition of goal and scope, development of life cycle inventories (LCIs), impact assessment, and interpretation of results [5]. The interpretation of results is an iterative step used to identify, qualify, and check the conclusions based on the assessment, and make any necessary changes. To incorporate a full sustainability assessment, environmental, economic, and social impacts are calculated using ELCA, LCC, and S-LCA methods, respectively. These results are used as the starting point for the application of MCDA methods to rank alternatives based on their sustainability performance. The MCDA portion of the study includes: structuring, elicitation, assessment, and recommendation [36]. 


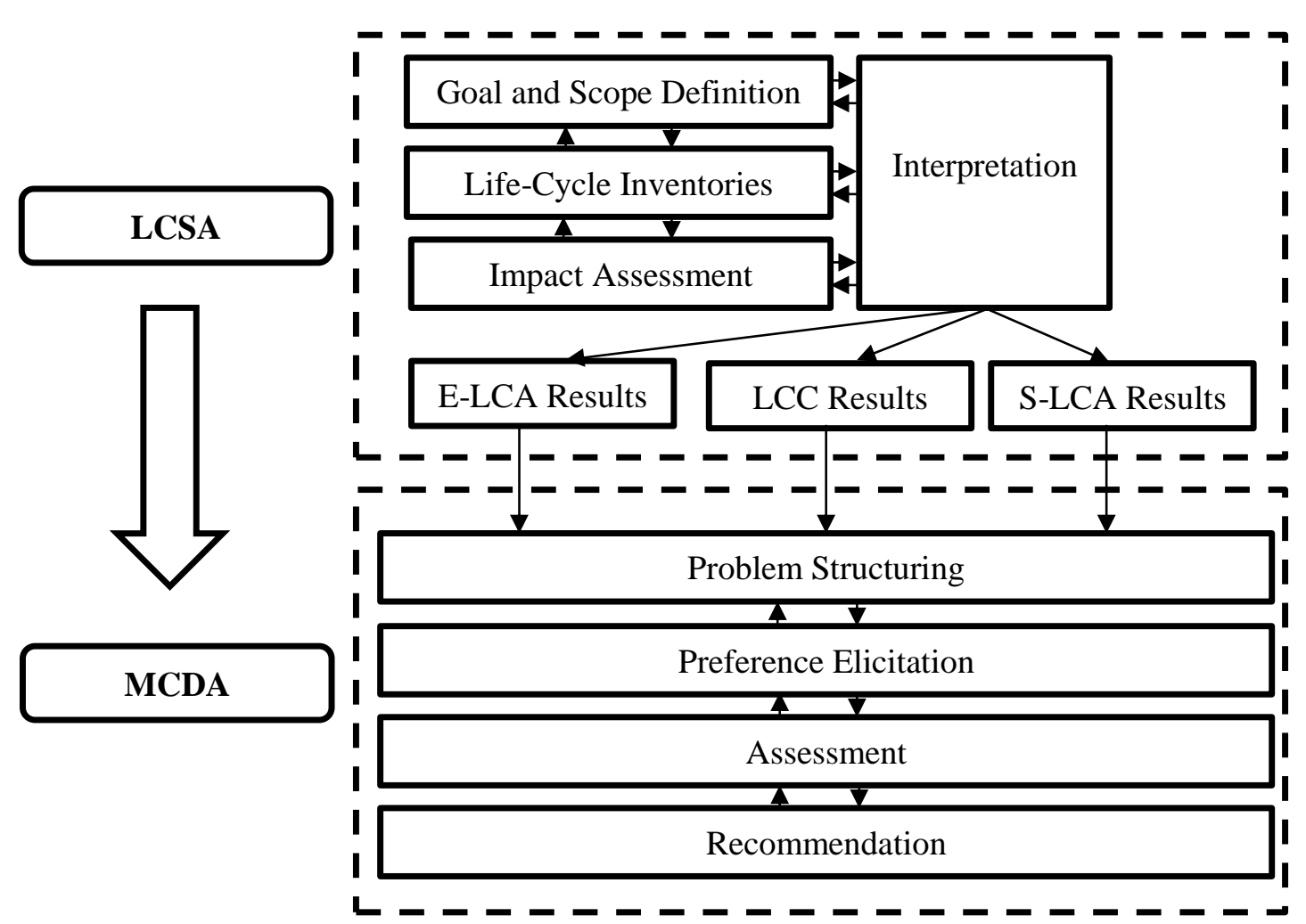

Figure 1. Assessment Framework

\subsection{Life Cycle Sustainability Assessment}

The LCSA is performed in a step-wise fashion, but the process is not necessarily linear. First, the goal and scope of the assessment is defined (Section 2.1.1). Second, data is collected in order to construct LCIs for each technology evaluated (Section 2.1.2). And third, sustainability indicators are selected to evaluate environmental, economic, and social impacts of the off-grid technologies (Section 2.1.3). Results are interpreted between each phase in order to identify, qualify, and check the conclusions based on the assessment, and make any necessary changes.

\subsubsection{Goal and Scope Definition}

The goal of this research is to assess the life-cycle sustainability impacts of meeting electricity and heating needs in an off-grid home, with the purpose to identify the trade-offs of an off-grid home compared to a grid-connected home. The system boundary includes the technologies that provide electricity and heat for an off-grid home. The life-cycle stages are divided into two phases: infrastructure, which includes the extraction, processing, and manufacturing of the systems (or fuels) along with the transportation of parts and final products; and operation and maintenance, which includes the use of the systems in the household and any services rendered throughout the system lifetime. The end-of-life is not considered as an explicit stage in this assessment due to lack of data regarding all systems, and the need to introduce too many assumptions.

Two off-grid households were selected as case studies for this evaluation, which will be referred to as Off-Grid Houses 1 and 2. Off-Grid House 1 uses the following off-grid electricity systems: $1.59 \mathrm{kWp}$ and $0.56 \mathrm{kWp}$ multi-crystalline silicone photovoltaic (PV) panels (which will be referred to as PV 1 and PV 2), a locally-built $0.3 \mathrm{~kW}$ pico-hydro generator, and a $5 \mathrm{~kW}$ petrol generator. These systems are connected to two lead-acid battery packs for storage. Heating needs, which include space and water heating as well as heat for cooking, are met through the 
use of the following off-grid heating systems: a wood burning furnace, a butane gas stove, and a solar cooker. Meanwhile, Off-Grid House 2 meets its electricity needs using a $1 \mathrm{~kW}$ microhydro generator connected to lead-acid and lithium-ion manganese oxide battery packs for storage. Heating needs are met through the use of a wood burning furnace, a butane gas stove, and a solar cooker.

Inventory and impact indicators are related to a common functional unit describing the technical and social utility of the product [7]. In this study, the product's utility is meeting the household's electricity and heating needs. The functional unit is defined as the electricity (in kilowatt hours $(\mathrm{kWh})$ ) and heat (in mega joules $(\mathrm{MJ})$ ) consumed by the household in order to satisfy its electricity and heating needs. It is important to note that in order to be reliable, the off-grid homes require systems that can generate more energy than is consumed. Thus, the energy consumed in each home is not representative of the potential energy that could be generated by the systems. We collected electricity and heat consumption data for the year 2017 to define each household's electricity and heating needs based on their annual consumption. Table 1 illustrates electricity consumption and Table 2 illustrates heat consumption in 2017 and the contribution of each technology to annual electricity and heat use, respectively.

Table 1. Household electricity consumption in 2017

\begin{tabular}{|c|c|c|c|}
\hline $\begin{array}{l}\text { Household } \\
\text { Off-Grid House } 1\end{array}$ & System & & Annual Electricity Consumption $(\mathrm{kWh})$ \\
\hline \multirow[t]{5}{*}{ Off-Grid House 1} & Petrol Generator & & $200(10 \%)$ \\
\hline & PV 1 & & $300(16 \%)$ \\
\hline & PV 2 & & $900(46 \%)$ \\
\hline & Hydro & & $540(28 \%)$ \\
\hline & & Total & $1940(100 \%)$ \\
\hline Off-Grid House 2 & Hydro & Total & $\begin{array}{l}1800(100 \%) \\
1800(\mathbf{1 0 0 \%})\end{array}$ \\
\hline
\end{tabular}

Table 2. Household heat consumption in 2017

\begin{tabular}{|c|c|c|}
\hline Household & System & Annual Heat Consumption (MJ) \\
\hline \multirow[t]{4}{*}{ Off-Grid House 1} & Wood Stove & $23450(94.53 \%)$ \\
\hline & Gas Stove & $1000(4.03 \%)$ \\
\hline & Solar Cooker & $358(1.44 \%)$ \\
\hline & Total & $24808(100 \%)$ \\
\hline \multirow[t]{4}{*}{ Off-Grid House 2} & Wood Stove & $7817(85.2 \%)$ \\
\hline & Gas Stove & $1000(10.9 \%)$ \\
\hline & Solar Cooker & $358(3.9 \%)$ \\
\hline & Total & $9175(100 \%)$ \\
\hline
\end{tabular}

We calculated the impacts of $1 \mathrm{kWh}$ of electricity and $1 \mathrm{MJ}$ of heat consumed in Off-Grid Houses 1 and 2 considering the contribution of each technology to total electricity and heat consumption in each home, respectively. These results are compared to a reference of $1 \mathrm{kWh}$ and $1 \mathrm{MJ}$ (consumed from the use of conventional electric heaters using the Joule effect) from the Portuguese electricity mix. We used a model of the Portuguese electricity mix developed by Garcia et al. [37], which takes into consideration the average electricity supply in the country from 2010-2014.

\subsubsection{Life-Cycle Model and Inventories}

Using a combination of household surveys, manufacturing specifications, published research in academic literature, and existing LCA databases, we developed LCIs for the technologies used 
to provide and store energy in the off-grid households. Tables 3-6 present the LCIs for electricity, storage, and heat systems, respectively. Foreground and operational data regarding electricity and heating consumption were collected based on site visits, interviews, and surveys with community members. Background data were obtained from the ecoinvent v3.0 database [38]. Data sources and key assumptions for the E-LCA, LCC, and S-LCA models are described in greater detail in sections S.1, S.2, and S.3 of the Supplementary Material.

Table 3. Summary of life-cycle inventory data of electricity systems

\begin{tabular}{lllllll}
\hline & \multicolumn{2}{l}{ Off-Grid House 1} & & & Off-Grid House 2 & Sources \\
\cline { 2 - 7 } & PV 1 & PV 2 & Hydro & Generator & Hydro & \\
\hline Power $(\mathrm{kW})$ & 1.59 & 0.56 & 0.3 & 5 & 1 & \\
Lifetime $(\mathrm{yrs})$. & 25 & 25 & 25 & 15 & 10 & {$[23],[39],[40]$} \\
Weight $(\mathrm{kg})$ & 198 & 78 & 25 & 76 & 25 & {$[40]$} \\
Consumption $(\mathrm{kWh} / \mathrm{yr})$. & 900 & 300 & 540 & 200 & 1800 & \\
Investment Cost $(€)$ & 10000 & 3500 & 1600 & 750 & 6100 & {$[41]$} \\
O\&M Cost $(€ /$ year) & 50 & 18 & 8 & 75 & 16 & {$[42]$} \\
Fuel Cost $(€ /$ year) & 0 & 0 & 0 & 188 & 0 & 1 \\
Local Persons Employed & 1 & 1 & 1 & 1 & 1 \\
\hline
\end{tabular}

Table 4. Summary of life-cycle inventory data of storage systems

\begin{tabular}{lllll}
\hline & Off-Grid House 1 & Off-Grid House 2 & & Sources \\
\cline { 2 - 5 } & Lead-Acid Batteries & Lead-Acid Batteries & Li-Ion Batteries & \\
\hline Battery Chemistry & $\mathrm{PbSO}_{4}$ & $\mathrm{PbSO}_{4}$ & $\mathrm{LiMn}_{2} \mathrm{O}_{4}$ & {$[43]$} \\
Capacity $(\mathrm{kWh})$ & 25.38 & 14.88 & 11.52 & {$[43]$} \\
Cycle Life & 1200 & 1200 & 2000 & \\
Weight $(\mathrm{kg})$ & 129 & 408 & 200 & {$[43]$} \\
Storage $(\mathrm{kWh} /$ lifetime $)$ & 30456 & 17856 & 23040 & \\
Investment Cost $(€)$ & 2994 & 2600 & 0 & \\
O\&M Cost $(€ /$ year) & 0 & 0 & 0 & 0 \\
Local Persons Employed & 1 & 0 & 0 & \\
\hline
\end{tabular}

Table 5. Summary of life-cycle inventory data of heating systems

\begin{tabular}{llllllll}
\hline & \multicolumn{2}{l}{ Off-Grid House 1 } & & Off-Grid House 2 & \multicolumn{2}{c}{ Sources } \\
\cline { 2 - 7 } & Furnace & $\begin{array}{l}\text { Gas- } \\
\text { Stove }\end{array}$ & $\begin{array}{l}\text { Solar } \\
\text { Cooker }\end{array}$ & Furnace & $\begin{array}{l}\text { Gas- } \\
\text { Stove }\end{array}$ & $\begin{array}{l}\text { Solar } \\
\text { Cooker }\end{array}$ \\
\hline Lifetime (yrs.) & 15 & 20 & 20 & 15 & 20 & 20 \\
Weight $(\mathrm{kg})$ & 180 & 15 & 11 & 180 & 15 & 11 \\
Consumption (MJ/yr.) & 23451 & 1000 & 358 & 7817 & 1000 & 358 \\
Investment Cost $(€)$ & 2000 & 100 & 300 & 2000 & 100 & 300 & \\
O\&M Cost $(€ /$ year) & 0 & 0 & 0 & 0 & 0 & 0 & {$[42]$} \\
Fuel Cost $(€ /$ year) & 180 & 52 & 0 & 60 & 26 & 0 & 0 \\
Local Persons Employed & 1 & 0 & 0 & 1 & 0 & 0 & \\
\hline
\end{tabular}

\subsubsection{Sustainability Indicators}

Although no defined standard to select sustainability indicators exists, the United Nations Environment Programme (UNEP) and the Society of Environmental Toxicology and Chemistry (SETAC) have set recommendations for their selection. These recommendations suggest that all indicators should: be relevant across the life cycle of the product, be considered across multidimensional perspectives, and acknowledge stakeholder's perspectives [7]. We chose indicators based on a combination of top-down and bottom-up approaches to ensure the robustness of assessing relevant issues. S.4 in the Supplementary material provides a summary of how these approaches were applied to determine the sustainability indicators used in this study (presented in Table 6). 
Table 6. Sustainability indicators for current study

\begin{tabular}{|c|c|c|c|}
\hline Sustainability Issue & Indicator & Unit & Source \\
\hline \multicolumn{4}{|l|}{ Environmental } \\
\hline Climate change & Global Warming & $\mathrm{g} \mathrm{CO}_{2}$-eq. $/ \mathrm{kWh}$ or $\mathrm{MJ}$ & [44] \\
\hline Energy demand & Non-Renewable Fossil Energy & $\mathrm{MJ}_{\text {primary }} / \mathrm{kWh}$ or $\mathrm{MJ}$ & [45] \\
\hline \multirow[t]{3}{*}{ Water use impact } & Freshwater Aquatic Ecotoxicity & $\mathrm{CTU}_{\mathrm{e}} / \mathrm{kWh}$ or $\mathrm{MJ}$ & [46] \\
\hline & Freshwater Eutrophication & g P-eq./kWh or MJ & [47] \\
\hline & Marine Eutrophication & g N-eq./kWh or $\mathrm{MJ}$ & [47] \\
\hline Air \& soil pollution & Terrestrial Acidification & $\mathrm{g} \mathrm{SO}_{2}$-eq./kWh or $\mathrm{MJ}$ & [47] \\
\hline \multicolumn{4}{|l|}{ Economic } \\
\hline \multirow[t]{3}{*}{ Financial Burden } & Investment Costs & $€ /$ Lifetime & N.A. \\
\hline & Operation \& Maintenance Costs & $€ /$ Lifetime & N.A. \\
\hline & Levelized Cost of Energy & $€ / \mathrm{kWh}$ or $\mathrm{MJ}$ & [41] \\
\hline \multicolumn{4}{|l|}{ Social } \\
\hline \multirow[t]{2}{*}{ Human Health } & Carcinogenic Toxicity & $\mathrm{CTU}_{\mathrm{h}, \mathrm{c}} / \mathrm{kWh}$ or MJ & [46] \\
\hline & Non-Carcinogenic Toxicity & $\mathrm{CTU}_{\mathrm{h}, \mathrm{nc}} / \mathrm{kWh}$ or $\mathrm{MJ}$ & [46] \\
\hline Local Employment & Number of local persons employed & $\#$ & N.A. \\
\hline
\end{tabular}

As illustrated in Table 6, four environmental issues were assessed, namely: climate change, energy demand, water use impact, air \& soil pollution, considering six environmental indicators: Global Warming (GW), Non-Renewable Fossil Energy Demand (nREn), Freshwater Aquatic Ecotoxicity (FAE), Freshwater Eutrophication (FE), Marine Eutrophication (ME), and Terrestrial Acidification (TA). The methods for calculating these indicators were selected based on the recommendations and guidelines published by the European Commission-Joint Research Centre (EC-JRC) and the UNEP/SETAC Initiative [48], [49]. GW was calculated using the characterization factor (CF) by the Intergovernmental Panel for Climate Change (IPCC) 2013 for the time horizon of 100 years [44]. The nREn was calculated using the Cumulative Energy Demand (CED) method [45]. The ReCiPe impact assessment method [47] was used to assess impacts in FE, ME, and TA, adopting an egalitarian midpoint approach. Finally, USEtox was chosen to evaluate FAE, presenting both "recommended" and "indicative" CFs following best practice recommendations [50]. The main difference between the two methods is that the "indicative" CFs calculate the impacts of the metals, dissociating substances, and amphiphilic substances; while the "recommended" does not, due to the relatively high uncertainty of addressing the fate of these chemicals within substance groups [46]. The financial feasibility assessment of the energy provisioning systems in the off-grid homes were based on three indicators: Investment Cost, Operation \& Maintenance (O\&M) Cost, and the Levelized Cost of Energy (LCOE). Finally, social impacts were evaluated based on impacts to human health and local employment using three indicators: Carcinogenic Toxicity (CT), Non-Carcinogenic Toxicity (NCT), and Local Employment. USEtox was chosen to evaluate CT and NCT, presenting both "recommended" and "indicative" CFs based on best practice recommendations [50]. We developed an indicator to calculate local employment. The homeowners were asked to report the number of local persons (people within the Benfeita community) involved during the building, installation, or maintenance of each system.

\subsection{Multi-Criteria Decision Analysis}

As they currently stand, both off-grid households meet electricity and heating needs through stand-alone and completely off-grid systems. The results of the LCSA provide the environmental, economic, and social impacts of these stand-alone systems, but they do not answer the question of whether these systems, or other alternatives, are the most sustainable means of meeting energy needs for these homes. In order to evaluate whether the stand-alone systems are the most sustainable option, we consider four hypothetical combinations of 
electricity and heating systems to meet the energy needs of each home: Baseline, A1, A2, A3, and A4. The Baseline refers to the systems currently in place, which are stand-alone off-grid electricity and heating systems. A1 describes a scenario where the grid is extended and connected to the home so that all electricity is consumed from the grid, and heating needs are met by off-grid heating systems. A2 describes a scenario where the grid is extended and connected to the home so that all electricity and heating needs are met by consuming electricity from the grid. A3 describes a scenario where the grid is extended and connected to the home to allow for excess electricity, not consumed from off-grid technologies, to be sold back to the grid, and where heating needs are met by off-grid heating systems. Finally, A4 describes a scenario where the grid is extended and connected to the home to allow for excess electricity, not consumed from off-grid technologies to be sold back to the grid, and where heating needs are met by consuming electricity from the grid.

For the purposes of this study, Multi-Attribute Value Theory (MAVT) is applied and the robustness of results is tested using Stochastic Multi-Criteria Acceptability Analysis (SMAA) and Variable Interdependent Parameter Analysis (VIP). MAVT is broken down into two main steps: building a value function for each criterion, and then computing a global value for each alternative so they can be ranked [51]. We depicted value functions and computed the global values using JSMAA, an open-source software that allows for MAVT (along with other MCDA) computations [52]. There are various elicitation techniques available to determine preferences from a DM in order to depict value functions. The choice of elicitation method is based on which method will better help the DM define their preferences. We chose to apply the bisection method [53], because it is easy to communicate and visualize, and therefore facilitates the elicitation process. After developing value functions for each criterion, we ask our DM to determine the scaling coefficients (k-value) for each criterion using the swings method [53]. Once points are determined for each criterion, they are summed, and scaling coefficients are assigned to each criterion by dividing $\mathrm{k}_{\mathrm{i}}$ by the sum of total points. These values are then used to help determine scaling coefficients to determine weights for the global value. Finally, using the $\mathrm{k}$-values determined in the swings method and the value functions elicited for each criterion, we compute a global value $v\left(a_{i}\right)$ for each alternative $a_{i}$ using the additive model, whose equation is defined below (Eq. 1) [36], [51]:

$$
v\left(a_{i}\right)=\sum_{j=1}^{n} k_{j} v_{j}\left(a_{i}\right)=k_{1} v_{1}\left(a_{i}\right)+k_{2} v_{2}\left(a_{i}\right) \ldots k_{n} v_{n}\left(a_{i}\right)
$$

A global value is then computed for each of the alternatives, with the highest value corresponding to the alternative most preferred by the DM in terms of sustainability. Once the global value was computed, a ranking was given from 1-5 on the sustainability of each alternative, with 1 being the most sustainable and 5 being the least sustainable option. Robustness of results is tested using SMAA and VIP. SMAA allows for the computation of results for additive models without specifying weight vectors [10]. By using rank acceptability indices and weights supporting a potential winning alternative, SMAA presents results by generating k-values considering probabilistic distributions [54]. Applying the JSMAA software [52], we evaluate the performance of each alternative to obtain a probability distribution for each alternative being placed in each rank. VIP analysis also allows for the computation of results for additive models through the use of linear programming to find the most extreme results that correspond to extreme weight vectors [10]. Using the VIP software [55], we evaluate the performance of each alternative to obtain a range of possible global values for each alternative. 


\section{Results and Discussion}

This section presents the life cycle sustainability impact assessment results obtained for the two off-grid homes. Environmental, economic, and social impacts are discussed in subsections 3.1, 3.2 , and 3.3, respectively. The results from the decision analysis assessment of energy provisioning alternatives are presented in 3.4.

\subsection{Environmental impacts}

Figure 2 illustrates the life-cycle impacts of consuming of $1 \mathrm{kWh}$ of electricity in Off-Grid Houses 1 and 2 compared to the reference of $1 \mathrm{kWh}$ in grid-connected homes. The environmental performance of the off-grid electricity systems compared to the reference varies depending on the impact category considered. Results for GW and nREn indicators show similar trends. The use of off-grid electricity has lower levels of GW and nREn because the majority of impacts, with the exception of the ones that come from the petrol generator, are realized during the systems' manufacturing stages and not their use; whereas consuming electricity from the Portuguese mix has high impacts in both the infrastructure and operation life-cycle stages because the mix includes the use of technologies (i.e. coal and natural gas plants) with high GHGs emissions and non-renewable energy content. In contrast, consuming electricity from the off-grid systems results in higher impacts of FAE, TA, ME, and FE (for Off-Grid House 2) due to upstream processes related to the manufacturing processes of these systems. FE depletion levels are higher for Off-Grid House 2 compared to the reference due to the presence of lithium-ion batteries, where the use of phosphates in the production process lead to FE. Section S.5 in the Supplementary Materials provides further details regarding the specific processes for the off-grid systems that contribute to each impact category. 


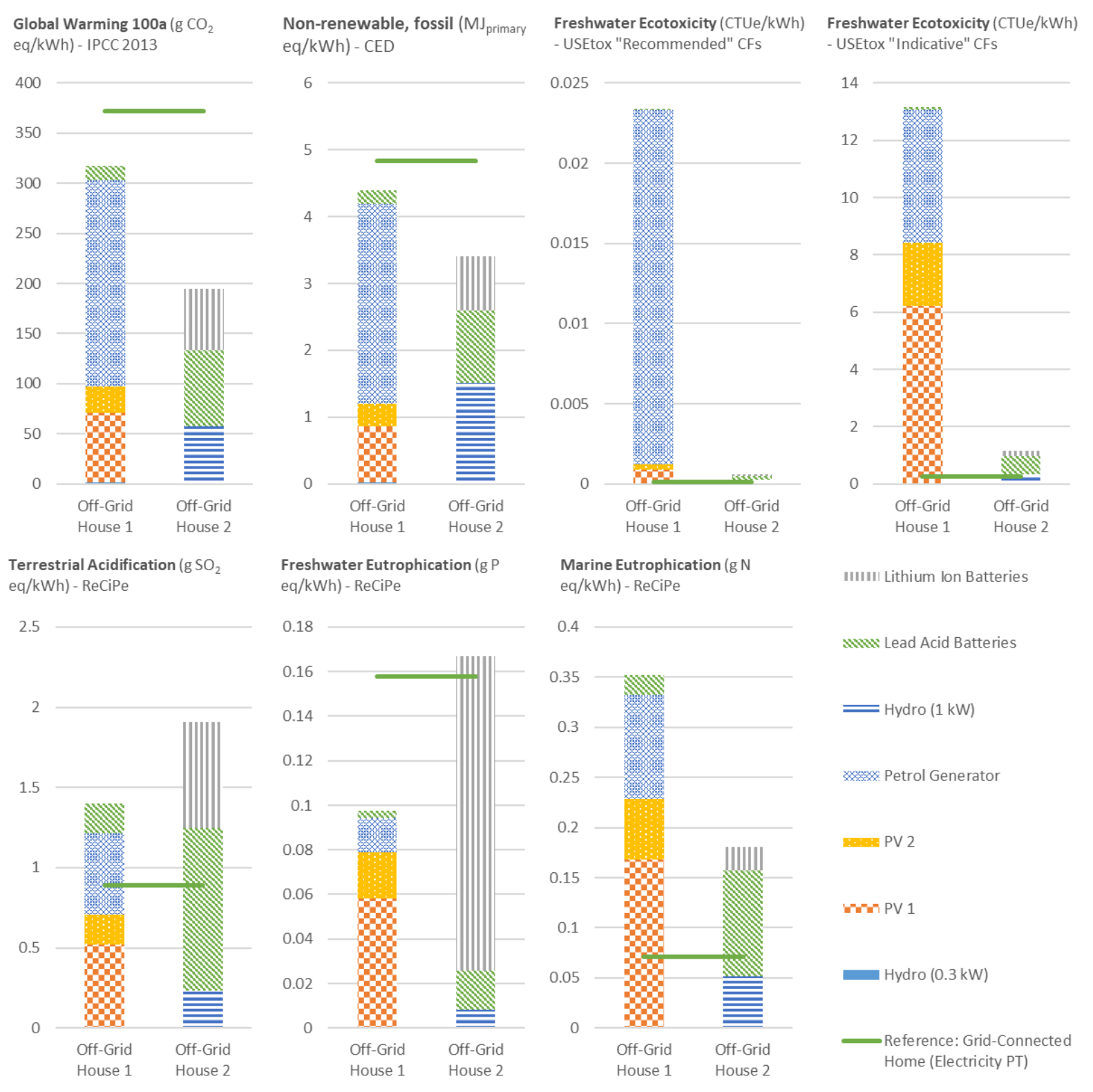

Figure 2. Environmental impacts of off-grid electricity consumption compared to a gridconnected home 
Figure 3 illustrates the life-cycle impacts of consuming of $1 \mathrm{MJ}$ of heat in an off-grid household compared to the reference of $1 \mathrm{MJ}$ of heat produced from electrical heaters in a grid-connected home. The off-grid systems outperform the reference considering the indicators of GW, nREn, TA, and FE. Meanwhile, they contribute to higher levels of FAE (considering "indicative" CFs) and ME than using electricity from the grid. Off-Grid House 1 slightly outperforms the reference in terms of FAE (considering "recommended" CFs), while Off-Grid House 2 underperforms the reference in this category. Section S.5 in the Supplementary Materials provides further details regarding the specific processes for the off-grid systems that contribute to each impact category.

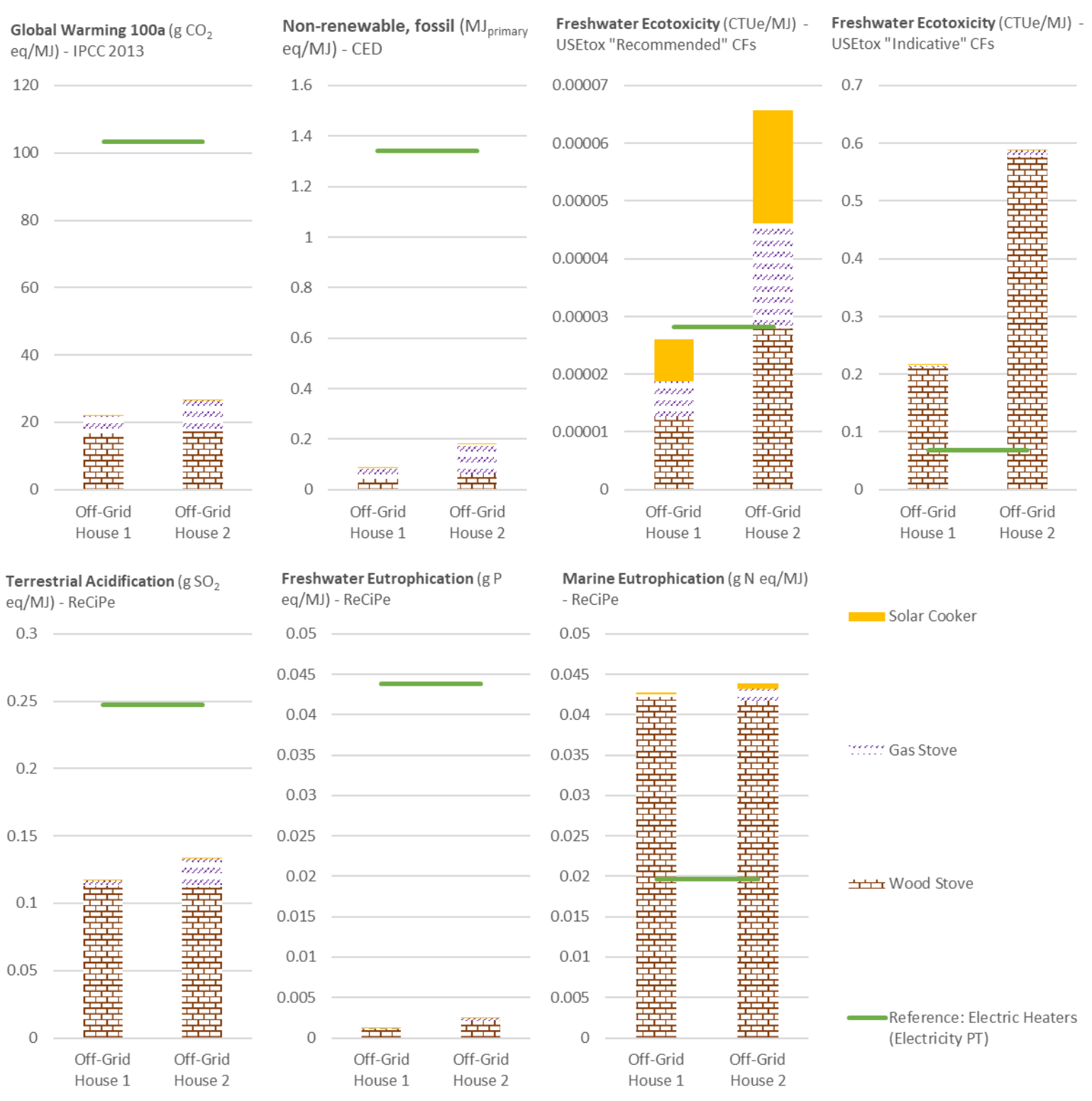

Figure 3. Environmental impacts of off-grid heat consumption compared to the use of electric heaters in a grid-connected home 


\subsection{Economic impacts}

Table 9 illustrates the economic assessment for the off-grid electricity and heating systems considering Investment Cost, O\&M Cost, and LCOE.

Table 7. Life-cycle costs of off-grid electricity and heating

\begin{tabular}{lllll}
\hline \multirow{2}{*}{ Electricity } & Indicator & $\begin{array}{l}\text { Off-Grid } \\
\text { House 1 }\end{array}$ & $\begin{array}{l}\text { Off-Grid } \\
\text { House 2 }\end{array}$ & $\begin{array}{l}\text { Reference (Cost of } \\
\text { Electricity from PT Grid) }\end{array}$ \\
& Investment $(€ /$ Lifetime) & 15850 & 19434 & \\
& O\&M $(€ /$ Lifetime) & 3012 & 160 & \\
& LCOE at a 1\% discount rate $(€ / \mathrm{kWh})$ & 0.66 & 0.82 & 0.28 \\
& LCOE at a 5\% discount rate $(€ / \mathrm{kWh})$ & 0.91 & 1.04 & 0.28 \\
& Investment $(€ /$ Lifetime) & 2400 & 2400 & \\
& O\&M $(€ /$ Lifetime) & 3740 & 1420 & \\
& LCOE at a 1\% discount rate $(€ / \mathrm{MJ})$ & 0.016 & 0.026 & 0.070 \\
& LCOE at a 5\% discount rate $(€ / \mathrm{MJ})$ & 0.019 & 0.034 & 0.070 \\
\hline
\end{tabular}

Considering a $1 \%$ discount rate, the cost of electricity from the grid is $57 \%$ lower than the LCOE of Off-Grid House 1, and 65\% lower than the LCOE of Off-Grid House 2. This is due to the fact that there is a high investment cost to installing these systems, and the homes do not have high levels of consumption. If the systems were installed for a household that had a higher electricity needs, or if the systems were shared with various households, the LCOE would decrease, because there is a zero-marginal cost of producing additional electricity by the systems. However, because the households are completely independent, they have to incur a large upfront cost for systems that are over dimensioned for their use. In contrast, considering a $1 \%$ discount rate, the use of off-grid heating is $52-74 \%$ cheaper than the reference because the households use inexpensive systems and consume little heat. In this case, it is to the household's advantage to invest in off-grid heat generation systems as opposed to conventional systems.

\subsection{Social impacts}

Figure 4 presents the social life-cycle impacts of consuming of $1 \mathrm{kWh}$ of electricity in an offgrid household compared to a grid-connected home. In general, off-grid electricity consumption has greater health impacts than the use of electricity from the grid. Consuming off-grid electricity has higher impacts in CT and NCT for both houses, with the exception of Off-Grid House 2, which shows lower levels of NCT when "recommended" CFs are taken into consideration. It is important to note that health impacts are mostly related to upstream processes during the manufacturing processes of all systems. The only exception are the impacts related to the emission of petrol with the use of the generator in Off-Grid House 1. This means that while off-grid systems contribute more to CT and NCT, these health impacts do not directly affect the local community. Section S.6 in the Supplementary Materials provides further details regarding the specific processes for the off-grid systems that contribute to each impact category. Meanwhile, the use of off-grid electricity stimulates higher level of Local Employment in Benfeita. In the case of Off-Grid House 1, all of the electricity and storage systems required the employment of local persons. The hydro system was completely built by the homeowner with the help of a local electrician, using materials that were purchased within Portugal and manufactured in Benfeita. Each PV system required the hiring of one local person to install when it was purchased, and the batteries required the hiring of a local person to connect to all of the electricity systems. The homeowner tends to hire one local person to conduct routine 
maintenance on the petrol generator. In the case of Off-Grid House 2, the homeowner hired a local electrician for the installation of his hydro system. In comparison, consuming electricity from the grid does not contribute to local employment because members of the Benfeita community would not be hired to either install or perform maintenance on the grid.

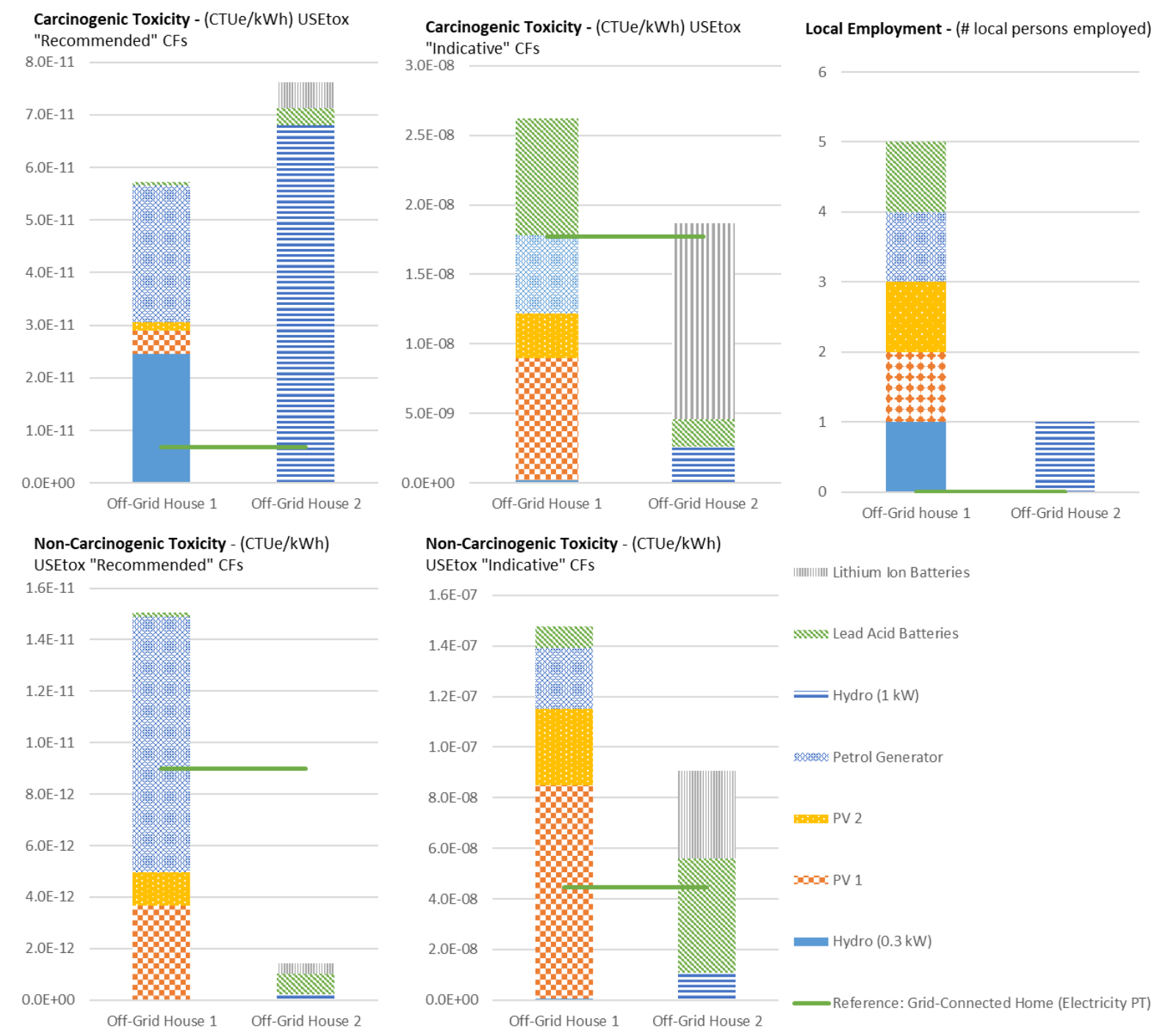

Figure 4. Social impacts of off-grid electricity consumption compared to a grid-connected home

Figure 5 illustrates the social life-cycle impacts of consuming of $1 \mathrm{MJ}$ of heat in an off-grid household compared to the reference of $1 \mathrm{MJ}$ of heat produced from electrical heaters in a gridconnected home. Compared to heating from the grid, off-grid heating use had lower impacts in CT and NCT considering both "recommended" and "indicative" CFs. Section S.6 in the Supplementary Materials provides further details regarding the specific processes for the offgrid systems that contribute to each impact category. The use of the off-grid heating technologies stimulated higher levels of Local Employment in Benfeita, because the homeowners contract a local person to deliver them wood at the beginning of the winter season. The other systems in the household do not contribute to local employment. 


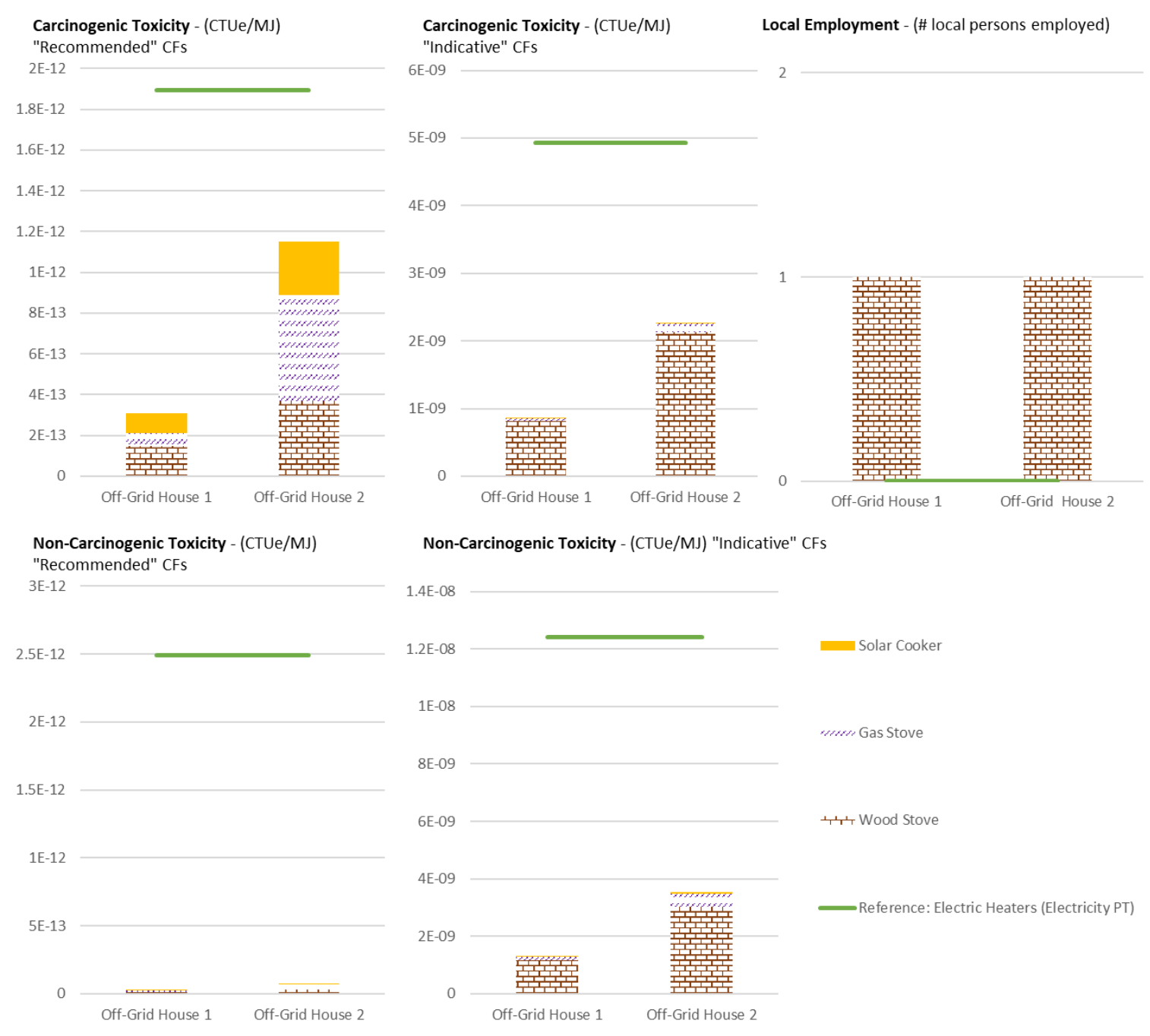

Figure 5. Social impacts of off-grid heat consumption compared to the use of electric heaters in a grid-connected home

\subsection{Multi-Criteria Decision Analysis}

In order to evaluate the sustainability of alternative energy scenarios, the homeowners were presented a performance table showing the percent difference from the Baseline for the four alternative scenarios considering the sustainability indicators assessed. For more details regarding the elicitation process, consult Section S.7 in the Supplementary Material. Figure 6 presents the stochastic and preference-based rankings of alternatives in Off-Grid House 1 considering "recommended" and "indicative" CFs for the toxicity impact categories (FAE, CT, and NCT) on the left and right, respectively. The stochastic rankings are based on probabilistic distribution of weight vectors using SMAA; each column represents the proportion of random weight vectors that place alternatives on a given position in the ranking. The preference-based rankings present the global value attained by the alternatives based on the results of the MAVT (shown in white) and the range of possible global values by each alternative based on the results of the VIP analysis, which uses linear programming to estimate results based on extreme weights (illustrated by the blue bar graphs). 


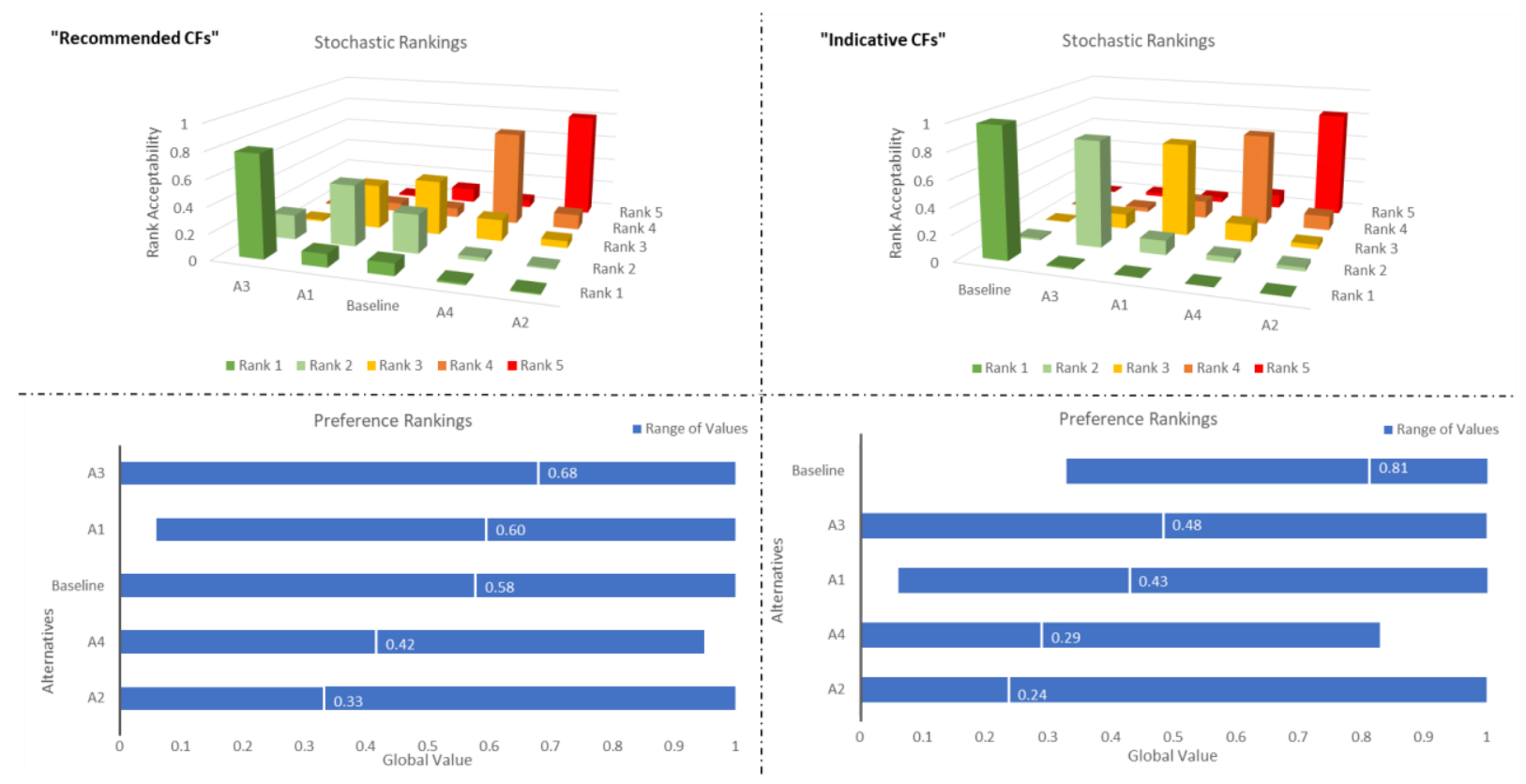

Figure 6. MCDA Results, Off-Grid House 1

When "recommended" factors are considered, A3 has a high probability of ranking first (78\%) compared to other alternatives due to better performance of its electricity and heating systems in many of the evaluated criteria. A1 and the Baseline compete for Ranks 2 and 3, with $\mathbf{A}_{1}$ having a higher probability of classifying as second and the baseline as third. A4 ranked fourth with a global value of 0.42 and $\mathbf{A} 2$ ranked fifth with a global value of 0.33 . The stochastic rankings for these alternatives provide robustness to these results, $73 \%$ of weight distributions rank $\mathbf{A}_{4}$ in fourth and $80 \%$ rank $\mathbf{A}_{2}$ in fifth. While the stochastic rankings of alternatives are quite constant, results from the VIP analysis show that under extreme weight considerations, almost all alternatives could score within the range of global values between 0 and 1 , with the exception of $\mathbf{A}_{\mathbf{4}}$, whose maximum possible score is 0.95 , and $\mathbf{A}_{\mathbf{1}}$, whose minimum possible score is 0.06 . The VIP analysis also confirms that no alternative is clearly dominated by another, meaning that no alternative can be completely discarded.

In contrast, the consideration of "indicative" CFs results in different rankings, the Baseline secures Rank 1, achieving a global value of 0.81 based on the DM's preferences. The SMAA verified the robustness of this result, as the Baseline will rank first $98 \%$ of the time based on a probabilistic distribution of weights. The results of the VIP analysis confirm that even under extreme weighting conditions, the Baseline could never achieve a lower global value than 0.33, while $\mathbf{A}_{1}$ has the possibility to score a global value of 0.06 and $\mathbf{A}_{2}-\mathbf{A}_{4}$ a global value of 0 . Based on the DM's preferences, A3 was ranked second with a global value of 0.48 , followed closely by $\mathbf{A}_{1}$ with a global value of 0.43 . This is consistent with the stochastic rankings, which place A3 in Rank 2 over $80 \%$ of the time and A1 in Rank 3 over $70 \%$ of the time. Based on the DM's preferences, A4 was ranked fourth and A2 ranked fifth, which is consistent with stochastic rankings which place $\mathbf{A}_{4}$ in fourth place over $70 \%$ of the time and $\mathbf{A}_{2}$ in fifth place over $82 \%$ of the time.

The consideration of "recommended" or "indicative" CFs presents different alternatives as the most sustainable. While the consideration of "recommended" factors highlights A3 as the best alternative, acknowledgement of "indicative" factors ranks the Baseline, an option that would rank third previously, as first. The primary reason for this divergence is due in large part to how 
each CF considers the environmental burdens in extending the grid. The acknowledgement of "indicative" factors takes into consideration the use of metals during grid extension in the calculation of toxicity factors. Because of this, alternatives that include the extension of the grid perform dramatically worse than when "recommended" factors are considered, which do not account for the use of metals in the calculation. This explains the drop in the ranking of $\mathbf{A} 3$ when "indicative" CFs are considered. Considering "recommended" CFs, the grid injection scenario for electricity and use of stand-alone heating systems presents the most benefits for this household. However, if the added burden of the metals used during the grid extension are acknowledged, this alternative is no longer the most attractive, and the benefits of a completely stand-alone system are greater. Even though "indicative" factors are accompanied by higher uncertainty, it is important to consider them because not acknowledging these impacts can lead to a skewed result. Thus, presenting results considering both CFs is beneficial because it provides a more comprehensive assessment of environmental impacts. The results for Off-Grid House 2 differ greatly from Off-Grid House 1, primarily due to the location of the homes and the types of systems utilized. Figure 7 presents the stochastic and preference-based rankings of alternatives in Off-Grid House 2 considering "recommended" and "indicative" CFs for the toxicity impact categories.

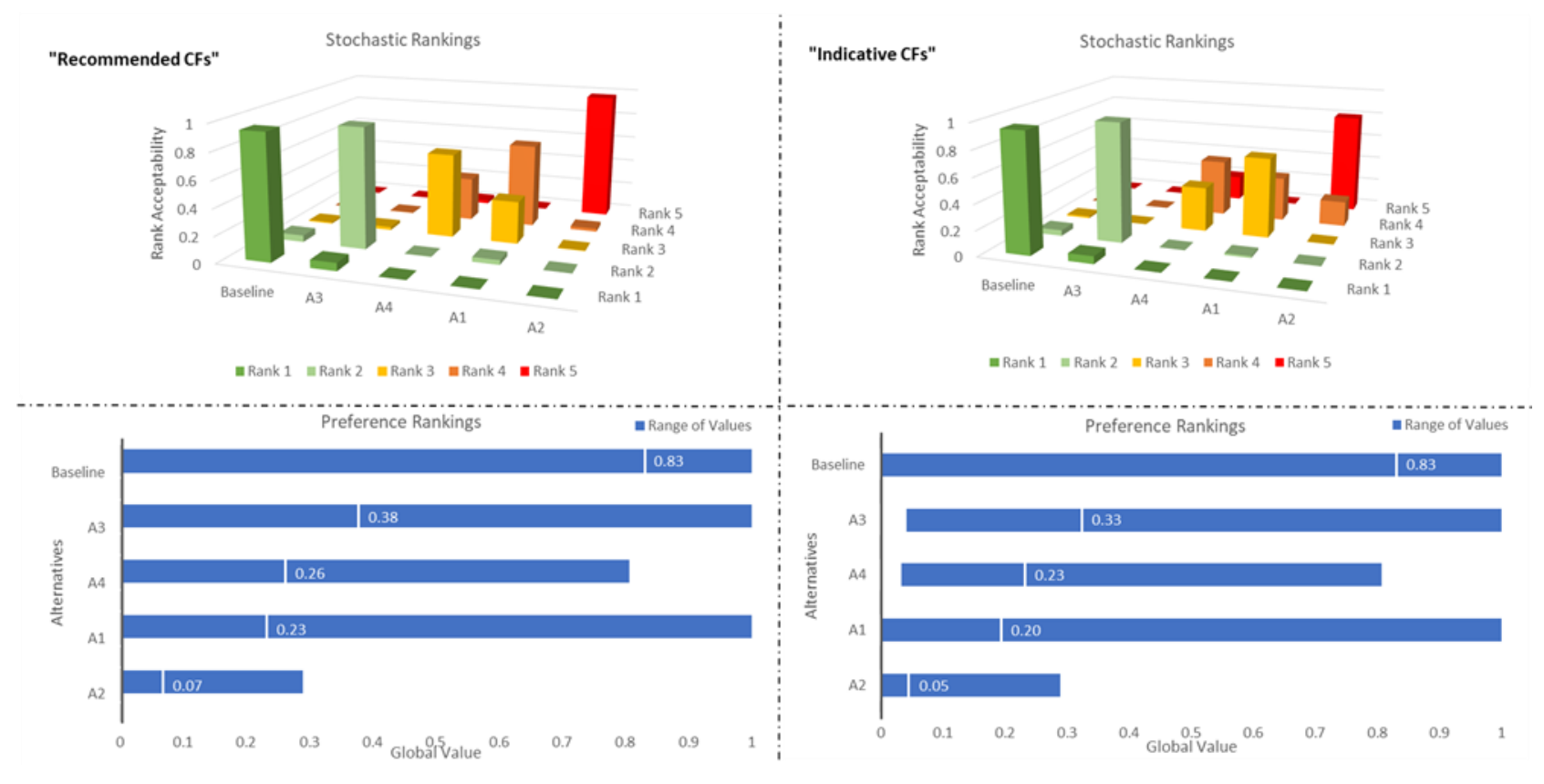

Figure 7. MCDA Results, Off-Grid House 2

Based on "recommended" CFs, the Baseline has a 93\% chance to be ranked first, which is consistent with the results using preference-based weights, where the alternative obtained the highest global value (0.83). A3 is ranked second $91 \%$ of the time, $\mathbf{A}_{4}$ has a higher probability to be ranked third and $\mathbf{A}_{1}$ ranked fourth. $\mathbf{A}_{2}$ is securely ranked fifth considering both calculation methods, with a $97 \%$ probability. The results of the VIP analysis confirm that no alternative is clearly dominated by another, however, A2 only has the possibility of achieving a maximum global value of 0.29 and $\mathbf{A} 4$ of 0.80 , while the other alternatives can achieve any value from 0 1 considering extreme weights. Considering "indicative" CFs, the Baseline is ranked first, with a global value of 0.83 based on elicited preferences. These results are robust, as the alternative has a 94\% likelihood of being ranked first considering a probabilistic distribution of weight vectors. A3 is ranked second $93 \%$ of the time, with a global value of 0.33 based on this DM's 
preferences. Compared to the results when "recommended" factors are considered, the distance between Rank 1 and Rank 2 in this scenario is slightly larger (0.50 versus 0.45$)$. Based on elicited preferences, $\mathbf{A}_{\mathbf{4}}$ is ranked third and $\mathbf{A}_{\mathbf{1}}$ is ranked fourth. However, according to stochastic rankings, $\mathbf{A}_{4}$ has a higher probability to be ranked fourth than third (44\% versus $35 \%)$, and $\mathbf{A}_{1}$ has a higher probability to be ranked third than fourth (63\% versus $\left.35 \%\right)$. Finally, $\mathbf{A}_{2}$ is securely ranked fifth, with a global value of 0.05 based on the DM's preferences and an $80 \%$ chance of achieving that rank.

Both calculation methods rank the Baseline as the best alternative by a large margin. This is primarily due to the level of isolation of Off-Grid House 2, which is 900 meters away from the grid and isolated from the community. Because of this, the burdens from extending the grid to only one household are quite large. Considering "recommended" factors, at least five households that require grid connection would need to exist in this area to sufficiently lower the impacts from the grid extension so that the Baseline would no longer be ranked first. However, when "indicative" factors are considered, eight households in the area would have to be connected. The main difference between the two is that consideration of "indicative" CFs increases the distance between the alternative ranked first and the other alternatives. As "indicative" factors consider metals in their calculation of toxicity, impacts will be larger than when "recommended" factors are considered. In this case, the burdens from grid extension (which involves the use of metals) are important to the overall impacts of the system, thus whether or not metals are considered in the calculation has a drastic effect on the results.

\section{Conclusions and Recommendations}

This article assessed the sustainability of meeting electricity and heating needs in off-grid homes by performing a combined LCSA and MCDA study on two off-grid houses in Benfeita, a small village in Portugal that has attracted an ecologically inclined community. Two homes were selected to serve as case studies because they have unique energy needs as well as distinct resource constraints that require the use of different technologies, making them representative of diverse challenges of off-grid living. Based on site visits, interviews, and surveys with community members, inventories for these systems were developed and used to build original life-cycle models.

The sustainability of meeting energy needs in the off-grid homes, compared to using the grid, was found to be dependent on the criteria under consideration. Off-grid electricity use had lower impacts in GW and nREn, but higher levels of FAE, TA, FE, and ME; while off-grid heating use had lower impacts in GW, nREn, TA, and FE, and higher ones in FAE and ME. The cost of electricity from the grid was found to be $57-65 \%$ less expensive than that of off-grid electricity, but 108-288\% more expensive than off-grid heating. Off-grid electricity use had higher impacts in CT and NCT, while off-grid heating's were lower. The results of the USEtox impact categories (FAE, CT, NCT) were significantly different when "recommended" versus "indicative" characterization factors (CFs) were presented, thus the consideration of both is important to improve robustness of results. Both off-grid electricity and heating systems stimulated higher levels of Local Employment in Benfeita.

Baseline results (the current situation) were compared to four energy provisioning scenarios $\left(\mathbf{A}_{1}, \mathbf{A}_{2}, \mathbf{A}_{3}\right.$, and $\left.\mathbf{A}_{4}\right)$ using Multi-Attribute Value Theory (MAVT) to rank alternatives based on their sustainability performance. The scenarios considered the impacts of extending and connecting the grid to the homes to allow for either electricity consumption from the grid, or injection of excess electricity generated to the grid. The resulting ranking of alternatives was 
mainly dependent on the house's distance from the grid and whether "recommended" or "indicative" CFs were considered in USEtox calculations. The primary reason for this divergence is the way metals are accounted for in each CF. "Indicative" CFs take into consideration metals in the calculation of toxicity, and because grid extension requires the use of many metals, the impacts from grid extension are much higher compared to when "recommended" CFs are used, which omit metals due to the relatively high uncertainty of addressing the fate of these chemicals within substance groups.

While this analysis provides an in-depth exploration of the different technologies employed to generate heat and electricity in two off-grid homes, it is important to acknowledge limitations associated with this study. First, the work only considered two households in the context of one small village in Portugal. Further studies could replicate this methodology and apply it to other off-grid communities across different locations to evaluate how the sustainability performance of these homes varies across contexts. Second, there was a lack of detailed data available on Local Employment because the homeowners did not maintain records of such information. The collection of data, such as the number of hours worked by local employees, would provide a stronger indicator as opposed to the number of local persons employed.

Homeowners should consider the distance they are from the grid when deciding whether or not they should be fully off-grid. For remote homes, off-grid, renewable energy solutions provide a reliable and sustainable form of electricity and heating, required that homeowners have the upfront capital to invest in such systems. The selection of technologies utilized should be dependent on the context and local resources in order to maximize the efficiency of the systems. Homes that are close to the grid should evaluate the trade-offs between going off-grid and the potential to connect their renewable energy systems to the grid to sell excess generation. For groups of households that are close together, sharing renewable energy systems (i.e. a community solar/wind/hydro system) is an interesting option to consider. These type of synergies would avoid the over-dimensioning of individual stand-alone systems, allowing the systems to be used more efficiently. Furthermore, if the homes are interested in extending the grid, the burden of the grid extension would be divided amongst multiple homes as opposed to one home. Finally, homeowners that live in places with easy access to the grid, or are already connected to the grid, should not go off-grid. If they are looking to increase the sustainability of their energy consumption, they may consider the addition of renewable energy systems to their homes to lower their electricity consumption from the grid, save on their utility bill, and have an increased level of energy independence. Meeting household energy needs in a sustainable way requires an analysis of the local context and available resources. A consideration of each household's sustainability trade-offs is central to understanding the value of alternative possibilities for energy provisioning.

\section{Acknowledgements}

This work was supported by Fundação para a Ciência e a Tecnologia, Portugal (FCT) and the European Regional Development Fund (FEDER) under projects SABIOS (POCI-01-0145-FEDER-016765), SustainFor (POCI-01-0145-FEDER-016764), SET-LCA (CENTRO-01-0145-FEDER-030570), and T4ENERTEC (POCI-01-0145-FEDER-029820). This work was developed in the scope of the Energy for Sustainability Initiative of the University of Coimbra.

\section{Nomenclature}

CED Cumulative Energy Demand




$\begin{array}{ll}\text { CF } & \text { Characterization Factor } \\ \text { CT } & \text { Carcinogenic Toxicity } \\ \text { DM } & \text { Decision Maker } \\ \text { E-LCA } & \text { Environmental Life-Cycle Assessment } \\ \text { EC-JRC } & \text { European Commission-Joint Research Centre } \\ \text { FAE } & \text { Freshwater Aquatic Ecotoxicity } \\ \text { FE } & \text { Freshwater Eutrophication } \\ \text { GW } & \text { Global Warming } \\ \text { IPCC } & \text { Intergovernmental Panel for Climate Change } \\ \text { kWh } & \text { Kilowatt hour } \\ \text { LCA } & \text { Life-Cycle Assessment } \\ \text { LCC } & \text { Life-Cycle Costing } \\ \text { LCIs } & \text { Life-Cycle Inventories } \\ \text { LCOE } & \text { Levelized Cost of Electricity } \\ \text { LCSA } & \text { Life-Cycle Sustainability Assessment } \\ \text { MAVT } & \text { Multi-Attribute Value Theory } \\ \text { MCDA } & \text { Multi-Criteria Decision Analysis } \\ \text { ME } & \text { Marine Eutrophication } \\ \text { MJ } & \text { Mega joule } \\ \text { NCT } & \text { Non-Carcinogenic Toxicity } \\ \text { nREn } & \text { Non-Renewable Fossil Energy Demand } \\ \text { S-LCA } & \text { Social Life-Cycle Assessment } \\ \text { SETAC } & \text { Society of Environmental Toxicology and Chemistry } \\ \text { SMAA } & \text { Stochastic Multi-Criteria Acceptability Analysis } \\ \text { TA } & \text { Terrestrial Acidification } \\ \text { UNEP } & \text { United Nations Environment Programme } \\ \text { VIP } & \text { Variable Interdependent Parameter Analysis } \\ & \end{array}$




\section{References}

[1] P. Vannini and J. Taggart, Off the Grid: Re-Assembling Domestic Life. New York: Routledge, 2015.

[2] R. Khalilpour and A. Vassallo, "Leaving the grid: An ambition or a real choice?," Energy Policy, vol. 82, pp. 207-221, Jul. 2015.

[3] T. van der Schoor and B. Scholtens, "Power to the people: Local community initiatives and the transition to sustainable energy," Renew. Sustain. Energy Rev., vol. 43, pp. 666-675, Mar. 2015.

[4] E. Forde, "The ethics of energy provisioning: Living off-grid in rural Wales," Energy Res. Soc. Sci., vol. 30, pp. 82-93, Aug. 2017.

[5] International Organization for Standards, "ISO 14040:2006," 2006. [Online]. Available: https://www.iso.org/standard/37456.html. [Accessed: 15-Feb-2018].

[6] T. Guinée, Jeroen B, Heijungs, R., Huppes, G., Zamagni, A., Masoni, P., Buonamici, R., Ekvall, T., and Rydberg, "Life cycle assessment: past, present and future," Environ. Sci. Technol., vol. 45, no. 1, pp. 90-96, 2011.

[7] UNEP/SETAC Life Cycle Initiative, "Towards a Life Cycle Sustainability A ssessment: Making informed choices on products," UNEP/SETAC Life Cycle Initiative, 2011.

[8] V. Belton and T. J. Stewart, Multiple Criteria Decision Analysis: An Integrated Approach. Norwell: Kluwer Academic Publishers, 2002.

[9] L. C. Dias, F. Freire, and J. Geldermann, "Perspectives on Multi-Criteria Decision Analysis and Life-Cycle Assessment," in New Perspectives in Multiple Criteria Decision Making, M. Doumpos, J. R. Figueira, S. Greco, and C. Zopounidis, Eds. Springer, pp. 315-329, 2019.

[10] L. C. Dias, C. Passeira, J. Malça, and F. Freire, "Integrating life-cycle assessment and multi-criteria decision analysis to compare alternative biodiesel chains," Ann. Oper. Res., p. forthcoming.

[11] J. Ren, A. Manzardo, A. Mazzi, F. Zuliani, and A. Scipioni, "Prioritization of bioethanol production pathways in China based on life cycle sustainability assessment and multicriteria decision-making," Int. J. Life Cycle Assess., vol. 20, no. 6, pp. 842853, Jun. 2015.

[12] H. Karunathilake, K. Hewage, W. Mérida, and R. Sadiq, "Renewable energy selection for net-zero energy communities: Life cycle based decision making under uncertainty," Renew. Energy, vol. 130, pp. 558-573, Jan. 2019.

[13] J. Seppälä, L. Basson, and G. A. Norris, "Decision Analysis Frameworks for LifeCycle Impact Assessment," J. Ind. Ecol., vol. 5, no. 4, pp. 45-68, Sep. 2001.

[14] E. Mallia and G. Lewis, "Life cycle greenhouse gas emissions of electricity generation 
in the province of Ontario, Canada," Int. J. Life Cycle Assess., vol. 18, no. 2, pp. 377391, Feb. 2013.

[15] R. Garcia, P. Marques, and F. Freire, "Life-cycle assessment of electricity in Portugal," Appl. Energy, vol. 134, pp. 563-572, Dec. 2014.

[16] E. Martínez, E. Jiménez, J. Blanco, and F. Sanz, "LCA sensitivity analysis of a multimegawatt wind turbine," Appl. Energy, vol. 87, no. 7, pp. 2293-2303, Jul. 2010.

[17] E. Santoyo-Castelazo, H. Gujba, and A. Azapagic, "Life cycle assessment of electricity generation in Mexico," Energy, vol. 36, no. 3, pp. 1488-1499, Mar. 2011.

[18] M. Z. Akber, M. J. Thaheem, and H. Arshad, "Life cycle sustainability assessment of electricity generation in Pakistan: Policy regime for a sustainable energy mix," Energy Policy, vol. 111, no. September, pp. 111-126, 2017.

[19] J. Kabayo, P. Marques, R. Garcia, and F. Freire, "Life-cycle sustainability assessment of key electricity generation systems in Portugal," Energy, vol. 176, pp. 131-142, Jun. 2019.

[20] B. Atilgan and A. Azapagic, "An integrated life cycle sustainability assessment of electricity generation in Turkey,” Energy Policy, vol. 93, pp. 168-186, 2016.

[21] L. Stamford and A. Azapagic, "Life cycle sustainability assessment of UK electricity scenarios to 2070,” Energy Sustain. Dev., vol. 23, pp. 194-211, Dec. 2014.

[22] R. Turconi, A. Boldrin, and T. Astrup, "Life cycle assessment (LCA) of electricity generation technologies: Overview, comparability and limitations," Renew. Sustain. Energy Rev., vol. 28, pp. 555-565, 2013.

[23] D. D. Hsu et al., "Life Cycle Greenhouse Gas Emissions of Crystalline Silicon Photovoltaic Electricity Generation," J. Ind. Ecol., vol. 16, pp. S122-S135, Apr. 2012.

[24] D. Weisser, "A guide to life-cycle greenhouse gas (GHG) emissions from electric supply technologies,” Energy, vol. 32, no. 9, pp. 1543-1559, Sep. 2007.

[25] A. Pascale, T. Urmee, and A. Moore, "Life cycle assessment of a community hydroelectric power system in rural Thailand," Renew. Energy, vol. 36, no. 11, pp. 2799-2808, 2011.

[26] T. Li, A. P. Roskilly, and Y. Wang, "Life cycle sustainability assessment of gridconnected photovoltaic power generation: A case study of Northeast England," Appl. Energy, vol. 27, pp. 465-479, Oct. 2018.

[27] S. Moslehi and R. Arababadi, "Sustainability Assessment of Complex Energy Systems Using Life Cycle Approach-Case Study: Arizona State University Tempe Campus," Procedia Eng., vol. 145, pp. 1096-1103, Jan. 2016.

[28] B. Fleck and M. Huot, "Comparative life-cycle assessment of a small wind turbine for residential off-grid use," Renew. Energy, vol. 34, no. 12, pp. 2688-2696, Dec. 2009. 
[29] R. García-Valverde, C. Miguel, R. Martínez-Béjar, and A. Urbina, "Life cycle assessment study of a $4.2 \mathrm{kWp}$ stand-alone photovoltaic system," Sol. Energy, vol. 83, no. 9, pp. 1434-1445, Sep. 2009.

[30] F. G. Üçtuğ and A. Azapagic, "Environmental impacts of small-scale hybrid energy systems: Coupling solar photovoltaics and lithium-ion batteries," Sci. Total Environ., vol. 643, pp. 1579-1589, Dec. 2018.

[31] E. A. Alsema, "Environmental life cycle assessment of solar home systems," Tech. rep. NWS-E-2000-15, 2000. [Online]. Available:

https://www.researchgate.net/publication/266339822_Environmental_Life_Cycle_Asse ssment_of_Solar_Home_Systems.

[32] D. O. Akinyele and R. K. Rayudu, "Techno-economic and life cycle environmental performance analyses of a solar photovoltaic microgrid system for developing countries," Energy, vol. 109, pp. 160-179, Aug. 2016.

[33] A. Bilich et al., "Life Cycle Assessment of Solar Photovoltaic Microgrid Systems in Off-Grid Communities," Environ. Sci. Technol., vol. 51, no. 2, pp. 1043-1052, Jan. 2017.

[34] C. Smith et al., "Comparative Life Cycle Assessment of a Thai Island's diesel/PV/wind hybrid microgrid," Renew. Energy, vol. 80, pp. 85-100, Aug. 2015.

[35] J. Ren, "Multi-criteria decision making for the prioritization of energy systems under uncertainties after life cycle sustainability assessment," Sustain. Prod. Consum., vol. 16, pp. 45-57, Oct. 2018.

[36] L. C. Dias, S. Silva, and L. Alçada-Almeida, "Multi-criteria environmental performance assessment with an additive model," in Handbook of Research Methods and Applications in Environmental Studies, M. Ruth, Ed. Cheltenham: Edward Elgar Publishing Limited, 2015, pp. 450-472.

[37] R. Garcia, P. Marques, and F. Freire, "Life-cycle assessment of electricity in Portugal," Appl. Energy, vol. 134, pp. 563-572, Dec. 2014.

[38] G. Wernet, C. Bauer, B. Steubing, J. Reinhard, E. Moreno-Ruiz, and B. Weidema, "The ecoinvent database version 3 (part I): overview and methodology," Int. J. Life Cycle Assess., vol. 21, no. 9, pp. 1218-1230, Sep. 2016.

[39] N. Jungbluth, M. Stucki, R. Frischknecht, and S. Büsser, "Photovoltaics," in Sachbilanzen von Energiesystemen: Grundlagen für den ökologischen Vergleich von Energiesystemen und den Einbezug von Energiesystemen in Ökobilanzen für die Schweiz, vol. 6-IV, no. 6, Roberto and Dones, Eds. Uster: ESU-services Ltd, 2010, p. v2.0.

[40] Cataylyst R\&D Ltd., "Assessing the carbon footprint of a PowerSpout," Report for EcoInnovation, 2009. [Online]. Available: http://catalystnz.co.nz/uploads/PowerSpoutfootprint-Report-Nov09.pdf. [Accessed: 20-Jun-2018].

[41] International Renewable Energy Agency, "Hydropower," Renewable Energy 
Technologies: Cost Analysis Series, 2012. [Online]. Available:

http://www.irena.org/documentdownloads/publications/re_technologies_cost_analysishydropower.pdf. [Accessed: 18-Dec-2018].

[42] Global Petrol Prices, "Portugal gasoline prices," 2018. [Online]. Available: https://www.globalpetrolprices.com/Portugal/gasoline_prices/. [Accessed: 03-Sep2018].

[43] C. Spanos, D. E. Turney, and V. Fthenakis, "Life-cycle analysis of flow-assisted nickel zinc-, manganese dioxide-, and valve-regulated lead-acid batteries designed for demand-charge reduction," Renew. Sustain. Energy Rev., vol. 43, pp. 478-494, Mar. 2015.

[44] IPCC, Climate Change 2013 - The Physical Science Basis. Cambridge: Cambridge University Press, 2013.

[45] R. Frischknecht et al., "Implementation of Life Cycle Impact Assessment Methods," Final report ecoinvent v2.2 No. 3. Swiss Centre for Life Cycle Inventories, Dübendorf, CH., 2007.

[46] R. K. Rosenbaum et al., "USEtox - the UNEP-SETAC toxicity model: recommended characterisation factors for human toxicity and freshwater ecotoxicity in life cycle impact assessment," Int. J. Life Cycle Assess., vol. 13, no. 7, pp. 532-546, Nov. 2008.

[47] M. A. J. Huijbregts et al., "ReCiPe2016: a harmonised life cycle impact assessment method at midpoint and endpoint level," Int. J. Life Cycle Assess., vol. 22, no. 2, pp. 138-147, Feb. 2017.

[48] M. Hauschild et al., "Recommendations for Life Cycle Impact Assessment in the European context - based on existing environmental impact assessment models and factors (International Reference Life Cycle Data System - ILCD handbook),” 2011. [Online]. Available: http://publications.jrc.ec.europa.eu/repository/handle/JRC61049. [Accessed: 18-Dec-2018].

[49] UNEP/SETAC Life Cycle Initiative, "Global guidance for life cycle impact assessment indicators," 2016. [Online]. Available: https://www.lifecycleinitiative.org/trainingresources/global-guidance-lcia-indicators-v-1/. [Accessed: 10-May-2019].

[50] M. Bijster et al., "USEtox ${ }^{\circledR} 2.0$ Documentation (Version 1.1),” 2017. [Online]. Available: https://www.usetox.org/sites/default/files/assets/USEtox_Documentation.pdf.

[51] R. L. Keeney, "Using preferences for multi-attributed alternatives," J. Multi-Criteria Decis. Anal., vol. 14, no. 4-6, pp. 169-174, Jul. 2006.

[52] T. Tervonen, "JSMAA: open source software for SMAA computations," Int. J. Syst. Sci., vol. 45, no. 1, pp. 69-81, Jan. 2014.

[53] P. Goodwin and G. Wright, Decision analysis for management judgment, Fifth Edit. Wiley, 2014. 
[54] R. Lahdelma and P. Salminen, "SMAA-2: Stochastic Multicriteria Acceptability Analysis for Group Decision Making," Oper. Res., vol. 49, no. 3, pp. 444-454, Jun. 2001.

[55] L. C. Dias and J. N. Clímaco, "Additive aggregation with variable interdependent parameters: the VIP analysis software," J. Oper. Res. Soc., vol. 51, no. 9, pp. 10701082, Sep. 2000. 